\title{
Publication dilemmas
}

\section{Geoffrey Hughes}

$\mathrm{D}$ eceit, hoodwinking, bluffing, fraud - the latter defined as wrongful or criminal deception intended to result in financial or personal gain-occur in all walks of life, and medical publishing is no exception to the rule. Whatever word you want to use, the problem appears in several guises, ranging from plagiarism, to data manipulation and fabrication, to bias in results analysis and interpretation when authors are subject to conflicts from competing interests, through to uncertainty about who made what contribution when multiple authors are cited in a paper.

The British Medical Journal (BMJ) recently reported the findings of the Committee for Ethics in Science and Higher Education in Croatia, namely, that a Croatian academic obstetrician had committed plagiarism, a problem originally published in the same journal in 2006. ${ }^{1}$

In the last 2 years, Emergency Medicine Journal (EMJ) has come across three cases (that we know of) that caused us concern: one very serious and two much less so.

The first was a paper we received from China in 2005 on the topic of non-ST elevation acute myocardial infarction. An eagle-eyed member of our editorial team, given responsibility for the paper as is our normal process, was overcome with a feeling of déjà vu. A quick search soon discovered an almost identical paper published in 2003 in another journal, the only real difference being in some of the data and formatting of tables.

The two other cases, from the USA and the UK, far more trivial in import and almost certainly done unintentionally and in good faith, were similar to each other in that they came under the banner of dual submission, where authors submit a paper to more than one journal at the same time without letting the editors know. Both papers were accepted for publication in this journal, and just as we were about to go to press we discovered that they had been published (or were about to be) elsewhere. One of these discoveries happened fortuitously, as the paper in question was published in a sister journal of the BMJ Publishing Group. The second was only revealed when the author wrote to us asking us to withdraw his paper owing to its imminent publication elsewhere. Both these cases were submitted despite the prerequisite (stated in the "guidelines for authors" detailed on the EMJ website) that "all material submitted is assumed to be submitted exclusively to Emergency Medicine Journal unless the contrary is stated".

What mechanisms are available to help the medical (and scientific) publishing industry deal with these sorts of problems?

The Committee on Publication Ethics (COPE) was founded in 1997 to help address breaches of research and publication ethics. It is a voluntary body that provides a discussion forum and advice for scientific editors, and aims to find practical ways of dealing with issues and to develop good practice. ${ }^{2}$

It publishes guidelines on study design and ethics approval, data analysis, authorship, conflict of interests, the peer review process, redundant publication, plagiarism, media relations, advertising, and how to deal with misconduct.

Readers and authors may be unaware that there is also a code of conduct for editors of biomedical journals. Guidelines for good publication practice were developed after wide consultation with editors and publishers. The code sets standards of good editorial conduct, asking editors to take seriously their role as guardians of biomedical science by taking all reasonable steps to ensure that allegations of research misconduct are properly investigated. There is also a mechanism for dealing with complaints against the journal not resolved by its own complaints process, a service only available to COPE members.

For those readers interested in these matters, a visit to the COPE website ${ }^{2}$ will be well rewarded; a trawl through the listed cases that COPE has investigated over the years will be both fascinating and instructive. Most readers will probably be surprised at the size, range and delineation of material handled.

Clearly, the ability to detect problems will vary, depending on their type. Matters related to study design, data manipulation, conflicts from competing interests and so on are likely to be detected by a good review from alert reviewers. Matters of plagiarism, dual submission and frank duplication of work published by someone else elsewhere are far more difficult to detect, and to a large extent are dependent on serendipity.

What did we do with the three cases mentioned earlier? In the minor cases, we wrote to the authors and the editors of the other journals, advising them of the problem and to heed it in the future. For the paper from China, we wrote to the authors asking for an explanation. When none was forthcoming we referred the matter to COPE; they confirmed and supported our stance and, as well as informing the editors of the journal in which the original paper was published, advised us to write to the authors again as well as the head of their medical institution, expressing our grave concern, asking a few formal and challenging questions and offering some recommendations for the institution to consider acting on. We await their response.

Emerg Med J 2007;24:610. doi: 10.1136/emj.2007.051987

Correspondence to: Geoffrey Hughes, Emergency Department, Royal Adelaide Hospital, North Terrace, Adelaide 5000,

Australia; cchdhb@yahoo.com

Accepted 29 June 2007

Competing interests: None declared.

\section{REFERENCES}

1 Watts G. Croatian academic is found guilty of plagiarism. BMJ, 2007;334, 1077.

2 Committee on Publication Ethics. http:// www.publicationethics.org.uk. 